\title{
A Rare Case of Epileptic Seizure After-effect Resulting in Nontraumatic Spontaneous Subdural Hemorrhage
}

\author{
Shalendra Singh ${ }^{1}$, Ashutosh Kaushal ${ }^{2}$, Rashmi Datta ${ }^{3}$, Rijesh R Unnithan ${ }^{4}$, Nitasha Mishra ${ }^{5}$
}

\begin{abstract}
Generalized tonic-clonic seizures (GTCS) result in diverse physiological alterations that are mostly short-lived and rarely lead to immediate serious consequences. Some early serious complications reported are head trauma and aspiration. While most cases of seizures are diagnosed readily from clinical history, some cases remain indolent and present later. A brain hemorrhage can have varied manifestations that warrant every clinician to be vigilant in diagnosis and management to prevent life-threatening complications. Furthermore, many reports have described seizures in patients operated for subdural hematoma (SDH), but to the best of our knowledge, none reveals SDH after the seizure. We encountered an unexpected incident of severe SDH in a 32-year-old adult following witnessed GTCS.
\end{abstract}

Keywords: Brain hemorrhage, Generalized tonic-clonic seizures, Subdural hematoma.

Indian Journal of Critical Care Medicine (2020): 10.5005/jp-journals-10071-23535

Generalized tonic-clonic seizures (GTCS) results in diverse physiological alterations that are mostly short lived and rarely lead to immediate serious consequences. Some early serious complications reported are head trauma and aspiration. ${ }^{1}$ While most cases of seizures are diagnosed readily from clinical history, some cases remain indolent and present later. A brain hemorrhage can have varied manifestations that warrant every clinician to be vigilant in diagnosis and management to prevent life-threatening complications. Furthermore, many reports have described seizures in patients operated for subdural hematoma (SDH), but to the best of our knowledge, none reveals SDH after the seizure. We encountered an unexpected incident of severe SDH in a 32-year-old adult following witnessed GTCS.

A 32 -year-old $(68 \mathrm{~kg}, 168 \mathrm{~cm})$ male patient with no known comorbidities arrived in the intensive care unit (ICU) with chief complaints of left-sided weakness (motor power 4/5) and drowsiness following an episode of GTCS. He had a history of two episodes of seizures in the last 2 months before the present episode and diagnosed as medically intractable epilepsy after brain imaging. Each episode of GTCS lasted for 2-3 minutes. He was unaware of the events, even during the postictal phase. He visited our hospital after each event, and every time no abnormality was found on imaging. Angiography showed neither arteriovenous malformations nor signs of neoplasm or any brain pathology. He was put on various antiepileptic agents, including levetiracetam, lamotrigine, and carbamazepine. The patient was apparently asymptomatic before he suffered the last episode of seizure followed by reducing GCS. There was no history of head injury or any sign of head injury found on examination. The patient was hemodynamically stable with a pulse rate of 72 beats/minute and blood pressure of 122/72 mm $\mathrm{Hg}$. On evaluation, computed tomography imaging of the brain revealed $1.7 \mathrm{~cm}$ thickness $\mathrm{SDH}$ is involving the right parietotemporo-occipital region causing mass effect with midline shift by $5.9 \mathrm{~mm}$ (Fig. 1). The patient was taken up for right frontal temporal parietal hemicraniectomy and was given general anesthesia per the institutional protocol. Blood loss during the surgery was $600-700 \mathrm{~mL}$, and he was transfused 2 units of packed red blood cell and 4 units of fresh frozen plasma. The patient was
1,4 Department of Anaesthesiology and Critical Care, Armed Forces Medical College, Pune, Maharastra, India

${ }^{2}$ Department of Anaesthesiology and Critical Care, All India Institute of Medical Sciences, Rishikesh, Uttrakhand, India

${ }^{3}$ Department of Anaesthesiology and Critical Care, Command Hospital (WC), Chandigarh, India

${ }^{5}$ Department of Anaesthesiology and Critical Care, All India Institute of Medical Sciences, Bhubaneswar, Odisha, India

Corresponding Author: Shalendra Singh, Department of Anaesthesiology and Critical Care, Armed Forces Medical College, Pune, Maharashtra, India, Phone: +919466332207, e-mail: drsinghafmc@ gmail.com

How to cite this article: Singh S, Kaushal A, Datta R, Unnithan RR, Mishra N. A Rare Case of Epileptic Seizure After-effect Resulting in Nontraumatic Spontaneous Subdural Hemorrhage. Indian J Crit Care Med 2020;24(8):722-723.

Source of support: Nil

Conflict of interest: None

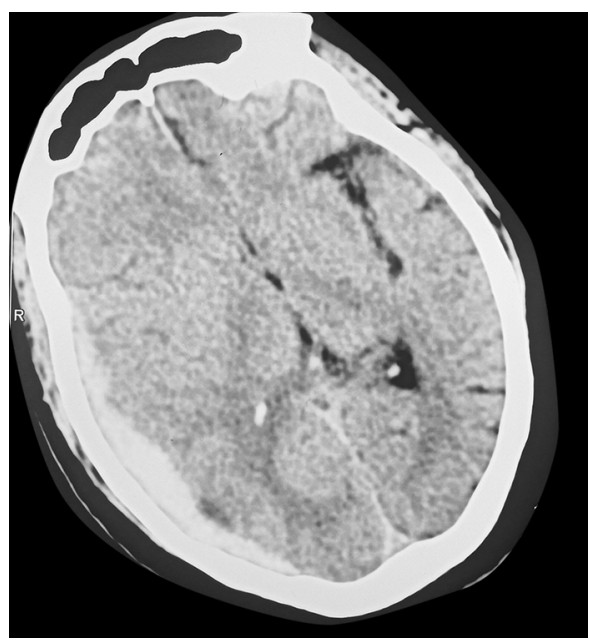

Fig. 1: Computed tomographic scan of head (axial view) showing subdural hematoma on the right parieto-temporo-occipital region with midline shift and mass effect

() The Author(s). 2020 Open Access This article is distributed under the terms of the Creative Commons Attribution 4.0 International License (https://creativecommons. org/licenses/by-nc/4.0/), which permits unrestricted use, distribution, and non-commercial reproduction in any medium, provided you give appropriate credit to the original author(s) and the source, provide a link to the Creative Commons license, and indicate if changes were made. The Creative Commons Public Domain Dedication waiver (http://creativecommons.org/publicdomain/zero/1.0/) applies to the data made available in this article, unless otherwise stated. 
electively ventilated overnight. The next morning, the patient was in full sensorium, and the trachea was extubated.

The etiology of nontraumatic SDH is rare, which is caused by various etiologies, such as coagulopathy, neoplasm's, cocaine, immunosuppressant therapy, and vascular lesions. ${ }^{2,3}$ One hypothesis of SDH following witnessed seizure (with no external injury) is that the increase in metabolism caused by GTCS results in an increase in cerebral blood flow that in turn increases intracranial pressure. Another hypothesis could be vigorous shaking of the head, causing the break of bridging vein results in $\mathrm{SDH} .{ }^{4}$ Although spontaneous SDH is rare in seizure patients, intensivist/neurologists should rule out SDH, which can be one of the causes of drowsiness and motor deficit after a seizure episode. A timely diagnosis requires a high index of suspicion in the setting of unconsciousness with unexplained low GCS in a seizure patient.

\section{References}

1. Mollaoğlu M, Bolayir E. Injuries in patients with epilepsy and some factors associated with injury. Noro Psikiyatr Ars 2013;50(3): 269-273.

2. Coombs JB, Combs BL, Chin EJ. Acute spontaneous subdural hematoma in a middle-aged adult: case report and review of the literature. J Emerg Med 2014;47(3):e63-e68. DOI: 10.1016/j. jemermed.2014.04.026.

3. Singh S, Sarin K, Rath GP. Surgical evacuation of subdural hematoma in a patient with transplanted heart under anesthesia. Saudi J Anaesth 2018;12(1):139-140. DOI: 10.4103/sja.SJA_154_17.

4. Geddes JF, Talbert DG. Paroxysmal coughing, subdural and retinal bleeding: a computer modelling approach. Neuropathol Appl Neurobiol 2006;32(6):625-634. DOI: 10.1111/j.1365-2990.2006. 00771.x. 